\title{
Silagem de capim-elefante adicionada de casca de abacaxi ${ }^{1}$
}

\author{
Caroline Salezzi Bonfá2*, Severino Delmar Junqueira Villela ${ }^{2}$, Gustavo Henrique de Frias Castro², \\ Roseli Aparecida dos Santos ${ }^{2}$, Antônio Ricardo Evangelista ${ }^{2}$, Otaviano de Souza Pires Neto ${ }^{2}$
}

$10.1590 / 0034-737 X 201764020010$

\begin{abstract}
RESUMO
Neste trabalho, foram avaliadas as características fermentativas e químico-bromatológicas da silagem de capimelefante (CE) com diferentes níveis de inclusão, durante a ensilagem, do coproduto da extração da polpa do abacaxi, a casca de abacaxi (CA), nas proporções de 0,$0 ; 12,5 ; 25,0 ; 37,5$ e 50,0\%, da matéria natural do capim-elefante. O material foi ensilado em silos laboratoriais e, após 180 dias, os silos foram abertos e coletaram-se amostras para a determinação dos teores de matéria seca (MS); carboidratos solúveis (CHOS); potencial hidrogeniônico (pH); nitrogênio amoniacal em percentagem do nitrogênio total $\left(\mathrm{NNH}_{3} / \mathrm{NT}\right)$; extrato etéreo $(\mathrm{EE})$; proteína bruta $(\mathrm{PB})$; proteína insolúvel em detergente neutro em percentagem do nitrogênio total (PIDN/NT); proteína insolúvel em detergente ácido em percentagem do nitrogênio total (PIDA/NT); fibra em detergente neutro (FDN); fibra em detergente ácido (FDA); celulose (CEL); lignina (LIG); nitrogênio insolúvel em detergente neutro (NIDN); nitrogênio insolúvel em detergente ácido (NIDA) e digestibilidade in vitro da matéria seca (DIVMS). Para a avaliação do efeito dos tratamentos, utilizou-se delineamento experimental inteiramente casualizado, com quatro repetições, executando-se o estudo de regressão para cada variável analisada $(\mathrm{P}<0,05)$. De acordo com as equações de regressão, para as características fermentativas, as silagens podem ser consideradas de muito boa qualidade. Quanto às frações fibrosas da silagem, a inclusão de níveis crescentes deste coproduto contribuiu para diminuí-las, o que pode ser confirmado pelos resultados encontrados para a DIVMS. A inclusão da CA durante a ensilagem do capim-elefante favorece a fermentação e melhora o valor nutritivo das silagens, sendo recomendada em todos os níveis de inclusão avaliados.
\end{abstract}

Palavras-chave: características fermentativas; coprodutos; ensilagem; qualidade da silagem.

\section{ABSTRACT}

\section{Elephant grass silage added with pineapple peel}

We evaluated the qualitative, fermentative, and chemical characteristics of elephant grass silage containing different levels of inclusion of coproduct of the pineapple pulp extraction, pineapple peel - $(0.0 \%, 12.5 \%, 25.0 \%, 37.5 \%$, and $50.0 \%$ ) in relation to natural field of elephant grass during ensiling. The material was ensiled in laboratory silos and after 180 days, the silos were opened and samples were collected for determination of dry matter, soluble carbohydrates, $\mathrm{pH}$, ammonia nitrogen in percentage of total nitrogen, ether extract, crude protein, neutral detergent insoluble protein as a percentage of total nitrogen, acid detergent insoluble protein as a percentage of total nitrogen, neutral detergent fiber, acid detergent fiber, cellulose, lignin, neutral detergent insoluble nitrogen, acid detergent insoluble nitrogen, and in vitro digestibility of dry matter. To assess the effect of the treatments, we used a completely randomized design with four replications, running the regression analysis for each variable analyzed $(\mathrm{P}<0.05)$. According to the regression equations for the fermentative characteristics, the silages can be considered of very good quality. As for fiber digestibility

\footnotetext{
Submetido em 12/09/2014 e aprovado em 05/04/2017.

${ }^{1}$ Este trabalho é parte da dissertação de mestrado da primeira autora; Projeto financiado pela FAPEMIG.

${ }^{2}$ Universidade Federal dos Vales do Jequitinhonha e Mucuri, Departamento de Zootecnia, Diamantina, Minas Gerais, Brasil. carolsalezzibonfa@yahoo.com.br; svillela@ufvjm.edu.br; gustavo.castro@ufvjm.edu.br; roseli.santos@ufvjm.edu.br; aricardo@dzo.ufla.br; opiresneto@gmail.com

*Autora para correspondência: carolsalezzibonfa@yahoo.com.br
} 
of silage, the increasing levels of this coproduct contributed to its decrease, which can be confirmed by the results found for in vitro digestibility of dry matter. The inclusion of the pineapple peel during the elephant grass silage fermentation promotes and improves the nutritive value of silages being recommended at all levels of inclusion evaluated.

Key words: coproducts; fermentation characteristics; silage; silage quality.

\section{INTRODUÇÃO}

O manejo integrado de pastagens deve ser implantado para mitigar o efeito da escassez de alimentos, nas épocas de seca, para utilização no período crítico do ano. A ensilagem é uma técnica convencional, utilizada para a conservação da forragem excedente, sendo o valor nutritivo da forragem um aspecto importante a ser considerado para que haja boa conservação do material ensilado (Cysne et al., 2006).

A qualidade da silagem depende do processo fermentativo dentro do silo e do valor nutritivo do material ensilado, uma vez que tem o propósito principal de manter o valor nutritivo o mais próximo possível do material que lhe deu origem. Porém, quando as gramíneas tropicais atingem elevado valor nutricional, apresentam alto teor de umidade, baixo teor de carboidratos solúveis e alto poder tampão, fatores que podem influenciar negativamente o processo fermentativo (Evangelista et al., 2004).

A composição química e o valor nutritivo das silagens podem ser modificados por meio de aditivos ao capim, no momento da ensilagem, os quais podem ser compostos por ácidos, sais, carboidratos fermentáveis ou culturas de bactérias láticas, além de enzimas. Os aditivos têm dois principais propósitos: influenciar o processo fermentativo, favorecendo a conservação dos alimentos, e melhorar o seu valor nutricional (Keplin, 2006). Entretanto, a utilização de aditivos não elimina os cuidados normais para obtenção de boas silagens, como a época de corte, a compactação da forragem e a vedação do silo (Pacheco et al., 2013).

Além disso, a utilização de coprodutos da agroindústria processadora de frutas na alimentação animal pode contribuir para a adoção de princípios de conservação do meio ambiente, visto que as agroindústrias têm grandes dificuldades em escoar os coprodutos, o que os torna potenciais causadores de contaminação ambiental.

Portanto, a utilização dos coprodutos agroindustriais em silagens de capim pode ser uma alternativa para melhorar as características químicas e fermentativas desses volumosos, pois atuam como fonte adicional de carboidratos para o processo fermentativo, elevam o valor nutritivo das silagens (Pompéu et al., 2006) e podem minimizar os danos e prejuízos causados ao ambiente, em função do desperdício de produtos com alto valor nutritivo (Pereira et al., 2009).

Objetivou-se, com este trabalho, avaliar os efeitos dos níveis crescentes de inclusão da casca de abacaxi sobre a qualidade da fermentação, as características químico-bromatológicas e a digestibilidade in vitro da matéria seca da silagem de capim-elefante.

\section{MATERIAL E MÉTODOS}

Este trabalho foi realizado no Departamento de Zootecnia da Universidade Federal dos Vales do Jequitinhonha e Mucuri (UFVJM), situada no Município de Diamantina, Minas Gerais, Brasil, com uso de coprodutos da agroindústria processadora de frutas FRUTIVALE, localizada em Datas, Minas Gerais.

Avaliou-se o efeito da casca do abacaxi, adicionada ao capim-elefante durante a ensilagem, nas proporções (níveis de inclusão) de 0,$0 ; 12,5 ; 25,0 ; 37,5$ e 50,0\%, da matéria natural do CE. Na Tabela 1 , encontra-se relacionada a composição químico-bromatológica do material utilizado na confecção das silagens e a do material com as diferentes inclusões da casca de abacaxi.

Utilizou-se, como volumoso para confecção da silagem, o capim-elefante (Pennisetum purpureum), proveniente de capineira pré-estabelecida, na Fazenda Experimental do Moura, pertencente à UFVJM, localizada em Curvelo, em Minas Gerais. O capim foi colhido manualmente, aos 150 dias de crescimento, com elevado teor de matéria seca. Esse material foi desintegrado em picadora estacionária, em partículas de 2 a $3 \mathrm{~cm}$, para ensilar associado à casca de abacaxi, que foi obtida após separação da casca do fruto para extração do suco. O coproduto, mesmo apresentando-se como uma massa pastosa, também foi desintegrado em picadora estacionária, para a obtenção de uma massa mais homogênea para a confecção das silagens.

Após a adição do coproduto à forragem, nas proporções descritas, o material foi homogeneizado e ensilado em silos laboratoriais, feitos de tubos de PVC de $100 \mathrm{~mm}$ de diâmetro e $450 \mathrm{~mm}$ de comprimento, e a compactação foi feita com o uso de soquetes de madeira. $\mathrm{O}$ material foi ensilado conferindo-se a densidade de $600 \mathrm{~kg} / \mathrm{m}^{3}$. Os silos foram identificados com tinta permanente e vedados com tampas de PVC providas de válvulas tipo Bunsen e, 
posteriormente, lacrados com fita adesiva e armazenados no Laboratório de Nutrição Animal (LNA) da UFVJM, em Diamantina-MG, em local arejado, seco e abrigado do sol e da chuva.

Após 180 dias, os silos foram abertos e, no mesmo momento, o material foi homogeneizado e parte do conteúdo de cada silo foi prensada com prensa hidráulica para a extração do suco da silagem, a partir do que uma parte foi utilizada para determinar os valores de $\mathrm{pH}$, empregando-se potenciômetro com escala expandida, da marca Tecnopon mPA 210, e outra parte foi conservada com ácido sulfúrico a $0,036 \mathrm{~N}(0,32 \%)$ e congelada para posterior determinação do teor de nitrogênio amoniacal, por destilação com óxido de magnésio (AOAC, 1995). As amostras de silagem foram pré-secadas em estufa de ventilação forçada, a $55^{\circ} \mathrm{C}$, por 72 horas (Silva \& Queiroz, 2002), sendo, em seguida, moídas em moinho estacionário com peneira de $1 \mathrm{~mm}$ (AOAC, 1995) e acondicionadas em potes plásticos para posteriores análises.

As análises químico-bromatológicas do material antes da ensilagem e das silagens resultantes, referentes aos teores de matéria seca, proteína bruta e extrato etéreo foram determinadas conforme AOAC (1995); os componentes da parede celular, de forma sequencial pelo método proposto por Van Soest et al. (1991); carboidratos solúveis em álcool, pelo método proposto por Bailey (1967). A determinação da digestibilidade in vitro da matéria seca foi executada, de acordo com a primeira fase do método descrito por Tilley e Terry (1963), no Laboratório de Nutrição Animal da Escola de Veterinária da UFMG, em Belo Horizonte, Minas Gerais.
Para a avaliação do efeito dos tratamentos, utilizou-se delineamento experimental inteiramente casualizado, com quatro repetições, conforme o modelo estatístico apresentado abaixo. Executou-se o estudo de regressão para cada variável analisada $(\mathrm{P}<0,05)$, por meio do PROC REG do software SAS 9.0 (SAS, 2002):

$Y i j=\mu+N j+e i j$,

em que: Yij = efeito da observação "i” no nível de inclusão “j”; $\mu=$ média geral; $\mathrm{Nj}=$ efeito do nível de inclusão “j” ( $j=0,0 \% ; 12,5 \% ; 25,0 \% ; 37,5 \%$ e $50,0 \%)$; eij = erro experimental.

\section{RESULTADOS E DISCUSSÃO}

A inclusão de níveis crescentes da casca de abacaxi propiciou decréscimo dos teores de matéria seca (MS) das silagens (Tabela 2), por causa do reduzido teor de MS presente no coproduto no momento da ensilagem (Tabela 1). Portanto, quanto maior a inclusão da casca de abacaxi, maior o teor de umidade adicionado ao material, o que é indesejável para ocorrência de processo fermentativo satisfatório dentro dos silos.

A inclusão do coproduto acima de $10 \%$ proporcionou a redução dos teores de MS das silagens a valores abaixo de $30 \%$, considerado como mínimo para um processo fermentativo satisfatório dentro dos silos (McDonald, 1981).

Em relação aos teores de CHOS, houve efeito significativo $(\mathrm{P}<0,05)$ (Tabela 2 ), em que a adição de $1 \%$ do coproduto do abacaxi corresponde ao aumento de 0,001 pontos percentuais nos teores de CHOS, evidenciando-

Tabela 1: Composição químico-bromatológica e digestibilidade in vitro da matéria seca da casca do abacaxi (CA), do capim-elefante ( $0,0 \%$ de nível de inclusão) e da mistura do capim-elefante (CE) com os diferentes níveis de inclusão (NI) da casca do abacaxi (CA) à ensilagem

\begin{tabular}{lrrrrrr}
\hline & & \multicolumn{5}{c}{ NI da CA } \\
\cline { 3 - 7 } & CA & $\mathbf{0 , 0 \%}$ & $\mathbf{1 2 , 5 \%}$ & $\mathbf{2 5 , 0 \%}$ & $\mathbf{3 7 , 5 \%}$ & $\mathbf{5 0 , 0 \%}$ \\
\hline MS (\%) & 25,68 & 45,03 & 42,61 & 40,19 & 37,77 & 35,35 \\
CHOs (\%) & 3,40 & 0,27 & 0,65 & 1,05 & 1,43 & 1,83 \\
EE (\%MS) & 1,86 & 2,33 & 2,26 & 2,20 & 2,14 & 2,09 \\
PB (\%MS) & 7,09 & 3,27 & 3,74 & 4,22 & 4,69 & 5,17 \\
PIDN/NT (\%PB) & 8,83 & 15,95 & 15,05 & 14,16 & 13,27 & 12,38 \\
PIDA/NT (\%PB) & 4,09 & 10,32 & 9,54 & 8,76 & 7,98 & 7,20 \\
FDN (\%MS) & 44,22 & 71,25 & 67,86 & 64,48 & 61,11 & 57,73 \\
FDA (\%MS) & 18,60 & 39,82 & 37,16 & 34,61 & 31,85 & 29,21 \\
CEL (\%) & 7,56 & 34,27 & 30,92 & 27,59 & 24,24 & 20,91 \\
LIG (\%) & 7,29 & 11,99 & 11,40 & 10,81 & 10,22 & 9,63 \\
NIDN (\%MS) & 0,10 & 0,08 & 0,08 & 0,08 & 0,08 & 0,09 \\
NIDA (\%MS) & 0,05 & 0,05 & 0,05 & 0,05 & 0,05 & 0,05 \\
DIVMS (\%MS) & 89,47 & 43,14 & 48,92 & 54,71 & 60,51 & 66,30 \\
\hline CE
\end{tabular}

CE - capim-elefante; CA - casca de abacaxi; NI - nível de inclusão; MS - matéria seca; CHOS - carboidratos solúveis; EE - extrato etéreo; PB - proteína bruta; PIDN/NT - proteína insolúvel em detergente neutro em percentagem do nitrogênio total; PIDA/NT - proteína insolúvel em detergente ácido em percentagem do nitrogênio total; FDN - fibra em detergente neutro; FDA - fibra em detergente ácido; CEL - celulose; LIG - lignina; NIDN - nitrogênio insolúvel em detergente neutro; NIDA - nitrogênio insolúvel em detergente ácido; DIVMS - digestibilidade in vitro da matéria seca. 
se o consumo dos CHOS durante o processo fermentativo, visto que, no momento da ensilagem, o coproduto apresentou 3,4\% de CHOS na MS (Tabela 1). Segundo Tomich et al. (2003), os carboidratos solúveis, ou açúcares (mono e dissacarídeos), são os principais substratos utilizados pelas bactérias láticas para a fermentação desejável no interior dos silos. A quantidade de carboidratos solúveis requerida para uma fermentação eficiente depende da quantidade de ácido que será necessária para a redução do pH a níveis apropriados à conservação do material ensilado, e que, segundo McDonald (1981), devem ser iguais ou inferiores a 3,8 unidades de $\mathrm{pH}$. De acordo com a equação de regressão, observou-se efeito significativo para os valores de $\mathrm{pH}$ à medida que se incluiu a casca de abacaxi na silagem, alcançando valores em unidade de $\mathrm{pH}$ de 3,71 nas silagens exclusivas de capim-elefante e de 3,54 unidades de $\mathrm{pH}$ em silagens com $50 \%$ de casca de abacaxi.

Observou-se efeito significativo para os teores de $\mathrm{NNH}_{3} / \mathrm{NT}$ entre as silagens de capim-elefante com diferentes níveis de inclusão da casca de abacaxi. Segundo a equação de regressão (Tabela 2), verificou-se comportamento linear decrescente com a inclusão do coproduto, alcançando-se teores próximos a 2,0\%, quando $50 \%$ de casca de abacaxi foram incluídos nas silagens.

Para avaliação dos produtos da fermentação dentro dos silos, quanto maior o teor de nitrogênio amoniacal, menor a qualidade da silagem, por degradação de compostos proteicos (proteína verdadeira, peptídios, aminoácidos, aminas e amidas) a amônia, principalmente pelas bactérias do gênero Clostridium (Cândido et al., 2007), ocasionada pela ocorrência de fermentações secundárias no material ensilado. A inclusão da casca do abacaxi favoreceu o processo fermentativo dentro dos silos, resultando em menores concentrações de nitrogênio amoniacal nas silagens.

Em relação aos teores de $\mathrm{PB}$, verificou-se aumento dessa fração com a inclusão de níveis crescentes de casca de abacaxi, alcançando-se teores próximos a 4,5\% de $\mathrm{PB}$, com a inclusão de $50 \%$ do coproduto, conforme equação de regressão apresentada na Tabela 3. A casca de abacaxi apresentou teor de PB mais elevado do que o do capim-elefante no momento da ensilagem (Tabela 1), proporcionando maior teor de $\mathrm{PB}$ nas silagens, em função do efeito aditivo com a sua inclusão no material ensilado. Comportamento semelhante foi observado no trabalho de Ferreira et al. (2009), em que os autores avaliaram o valor nutritivo da silagem de capim-elefante enriquecida com casca de abacaxi desidratada, com teores de $\mathrm{PB}$ próximos a 4,77\%, na silagem exclusiva de CE, e de 5,97\% de PB, nas silagens com o NI de $14 \%$.

Quanto aos teores de PIDN/NT, não houve efeito significativo $(\mathrm{P}>0,05)$ com a inclusão da casca de abacaxi nas silagens de capim-elefante, ou seja, para todos os níveis de inclusão, os teores de PIDN/NT foram iguais a $15,28 \%$. Houve efeito significativo $(\mathrm{P}<0,05)$ em relação aos teores de PIDA/NT (Tabela 3 ). Os teores de PIDA/NT diminuíram linearmente com a inclusão da casca de abacaxi, exibindo decréscimo de 0,069 pontos percentuais para cada $1 \%$ de inclusão do coproduto, mostrando que houve o efeito de diluição dessa fração, diminuindo seu teor com a inclusão do coproduto. Os teores de PIDN/NT e PIDA/NT representam a quantidade de nitrogênio do alimento que é lenta e parcialmente degradada, além da proteína indisponível no rúmen. A PIDN pode ser degradada mais lentamente do que a proteína presente no conteúdo celular; já a PIDA é pouco degradada e, dependendo de suas ligações com a lignina, faz com que a proteína seja indisponível para o animal. Portanto, quanto maior a percentagem de PIDN e PIDA em um alimento, menor ou mais lenta é a degradação da proteína (Freitas, 2011).

De acordo com os resultados encontrados neste trabalho, a adição da casca do abacaxi na ensilagem do capim-elefante proporcionou o aumento de PB nas silagens, associado a menores teores de PIDN e PIDA (Tabela 3), o que pode otimizar a utilização da PB pelos micro-organismos ruminais e favorecer a eficiência de utilização dos nutrientes contidos nas silagens, com implicações na taxa de degradação da fração fibrosa, consumo de forragem e desempenho animal (Minson, 1990; Anderson, 2000).

Tabela 2: Valores médios de matéria seca, carboidratos solúveis, $\mathrm{pH}$, nitrogênio amoniacal em percentual do nitrogênio total e extrato etéreo em função dos níveis de inclusão da casca de abacaxi $(0,0 \%, 12,5 \%, 25 \% ; 37,5 \%, 50 \%)$ na silagem de capim-elefante e equações de regressão, obtidas por meio da composição químico-bromatológica das silagens

\begin{tabular}{|c|c|c|c|c|c|c|c|c|c|}
\hline & \multicolumn{5}{|c|}{ NI da CA } & \multirow{2}{*}{ Equação } & \multirow{2}{*}{$\mathbf{R}^{2}$} & \multirow{2}{*}{$\mathbf{P}$} & \multirow{2}{*}{ CV } \\
\hline & $0 \%$ & $12,5 \%$ & $25 \%$ & $37,5 \%$ & $50 \%$ & & & & \\
\hline MS & 33,33 & 29,20 & 25,84 & 23,79 & 21,91 & $\mathrm{MS}=33,296-0,359 \mathrm{NI}+0,003 \mathrm{NI}^{2}$ & 0,95 & 0,0001 & 3,40 \\
\hline CHOS & 0,03 & 0,04 & 0,05 & 0,06 & 0,13 & $\mathrm{CHOS}=0,032+0,001 \mathrm{NI}$ & 0,45 & 0,0006 & 40,70 \\
\hline $\mathrm{pH}$ & 3,66 & 3,64 & 3,61 & 3,59 & 3,56 & $\mathrm{pH}=3,668-0,002 \mathrm{NI}$ & 0,26 & 0,0130 & 2,05 \\
\hline $\mathrm{NNH}_{3} / \mathrm{NT}$ & 3,3 & 2,98 & 2,67 & 2,36 & 2,05 & $\mathrm{NNH}_{3} / \mathrm{NT}=3,30-0,025 \mathrm{NI}$ & 0,43 & 0,0010 & 18,69 \\
\hline $\mathrm{EE}$ & 2,16 & 3,13 & 4,29 & 2,12 & 2,13 & $\mathrm{EE}=2,226+0,111 \mathrm{NI}-0,002 \mathrm{NI}^{2}$ & 0,41 & 0,0041 & 26,61 \\
\hline
\end{tabular}

NI - nível de inclusão; CA - casca de abacaxi; MS - matéria seca; $\mathrm{CHOS}$ - carboidratos solúveis; pH - potencial hidrogeniônico; NNH 3 /NT - nitrogênio amoniacal em percentual do nitrogênio total; EE - extrato etéreo; $\mathrm{R}^{2}$ - coeficiente de determinação da equação de regressão; $\mathrm{P}$ - nível de significância do modelo de regressão; CV - coeficiente de variação. 
Em relação aos teores de FDN, verificou-se comportamento linear decrescente $(\mathrm{P}<0,05)$, à medida que se aumentaram os níveis de inclusão da casca do abacaxi (Tabela 4). Os teores de FDN diminuíram linearmente à medida que se aumentou o nível de inclusão da casca do abacaxi, com decréscimo de 0,138 pontos percentuais para cada $1 \%$ de inclusão. Altos teores de FDN podem influenciar a ingestão de alimentos, em função do enchimento ruminal; em contrapartida, menores teores dessa fração representam ponto positivo na nutrição de ruminantes, uma vez que ela é apontada como um dos principais reguladores do consumo por sua lenta degradação e reduzida taxa de passagem.

Comportamento semelhante ao da FDN foi observado com os teores de FDA, pois, à medida que se aumentou o nível de inclusão da casca do abacaxi, diminuíram os teores dessa fração nas silagens, com decréscimo de 0,091 pontos percentuais para cada $1 \%$ de inclusão. A inclusão da casca do abacaxi na ensilagem diluiu a participação das frações fibrosas, por causa dos teores dessa fração do coproduto in natura (Tabela 1), o que pode favorecer o consumo e a digestibilidade da silagem de capim-elefante, com a inclusão da casca de abacaxi.

Verificou-se comportamento linear decrescente $(\mathrm{P}<$ 0,05) dos teores de CEL, conforme descrito pela equação de regressão apresentada na Tabela 4 , com decréscimo de 0,109 pontos percentuais para cada $1 \%$ de inclusão, alcançando-se teores de $24,91 \%$, quando $50 \%$ do coproduto foi adicionado. Como a casca de abacaxi, no momento da ensilagem, apresentou 7,56\% de CEL, e o capim-elefante, $34,27 \%$, houve o efeito de diluição desta fração nas silagens, ou seja, a adição desse coproduto possibilitou redução desse constituinte na parede celular, característica também observada nas variáveis FDN e FDA.

Quanto aos teores de LIG, não houve efeito significativo $(\mathrm{P}>0,05)$ com os crescentes níveis de inclusão da casca de abacaxi na silagem de capim-elefante. Em relação às concentrações de LIG encontradas na casca de abacaxi e no capim-elefante, no momento da ensilagem, os teores mantiveram-se próximos aos encontrados no material ensilado (Tabela 1), em torno de $8,26 \%$ na MS.

A redução dos constituintes da fração fibrosa com a adição da casca de abacaxi pode ser justificada pelo efei-

Tabela 3: Valores médios percentuais de proteína bruta, proteína insolúvel em detergente neutro em percentual do nitrogênio total e proteína insolúvel em detergente ácido em percentual do nitrogênio total em função dos níveis de inclusão da casca de abacaxi $(0,0 \%$, $12,5 \%, 25 \% ; 37,5 \%, 50 \%$ ) na silagem de capim-elefante e equações de regressão, obtidas por meio da composição químico-bromatológica das silagens

\begin{tabular}{|c|c|c|c|c|c|c|c|c|c|}
\hline & \multicolumn{5}{|c|}{ NI da CA } & \multirow{2}{*}{ Equação } & \multirow{2}{*}{$\mathbf{R}^{2}$} & \multirow{2}{*}{$\mathbf{P}$} & \multirow{2}{*}{ CV } \\
\hline & $0 \%$ & $12,5 \%$ & $25 \%$ & $37,5 \%$ & $50 \%$ & & & & \\
\hline $\mathrm{PB}$ & 3,75 & 3,91 & 4,07 & 4,24 & 4,40 & $\mathrm{~PB}=3,754+0,013 \mathrm{NI}$ & 0,18 & 0,0363 & 11,53 \\
\hline PIDN/NT & 14,25 & 16,00 & 15,07 & 15,58 & 15,53 & $\mathrm{PIDN} / \mathrm{NT}=15,28$ & - & $0,5520 *$ & 14,51 \\
\hline PIDA/NT & 7,71 & 6,85 & 5,99 & 5,12 & 4,26 & $\mathrm{PIDA} / \mathrm{NT}=7,716-0,069 \mathrm{NI}$ & 0,66 & 0,0001 & 15,02 \\
\hline
\end{tabular}

NI - nível de inclusão; CA - casca de abacaxi; PB - proteína bruta; PIDN/NT - proteína insolúvel em detergente neutro em percentual do nitrogênio total; PIDA/NT - proteína insolúvel em detergente ácido em percentual do nitrogênio total; $\mathrm{R}^{2}$ - coeficiente de determinação da equação de regressão; P - nível de significância do modelo de regressão; CV - Coeficiente de variação; * - modelo de regressão não significativo $(\mathrm{P}>0,05)$.

Tabela 4: Valores médios percentuais de fibra em detergente neutro, fibra em detergente ácido, celulose, lignina, nitrogênio insolúvel em detergente neutro, nitrogênio insolúvel em detergente ácido e digestibilidade in vitro da matéria seca em função dos níveis de inclusão da casca de abacaxi $(0,0 \%, 12,5 \%, 25 \% ; 37,5 \%, 50 \%)$ na silagem de capim-elefante e equações de regressão obtidas por meio da composição químico-bromatológica das silagens

\begin{tabular}{|c|c|c|c|c|c|c|c|c|c|}
\hline & \multicolumn{5}{|c|}{ NI da CA } & \multirow{2}{*}{ Equação } & \multirow{2}{*}{$\mathbf{R}^{2}$} & \multirow{2}{*}{$\mathbf{P}$} & \multirow{2}{*}{ CV } \\
\hline & $0 \%$ & $12,5 \%$ & $25 \%$ & $37,5 \%$ & $50 \%$ & & & & \\
\hline FDN & 70,52 & 68,80 & 67,07 & 65,34 & 63,62 & $\mathrm{FDN}=70,523-0,138 \mathrm{NI}$ & 0,75 & 0,0001 & 2,12 \\
\hline FDA & 39,03 & 37,89 & 36,76 & 35,62 & 34,48 & $\mathrm{FDA}=39,032-0,091 \mathrm{NI}$ & 0,70 & 0,0001 & 2,89 \\
\hline CEL & 29,98 & 28,62 & 27,26 & 25,89 & 24,53 & $\mathrm{CEL}=29,983-0,109 \mathrm{NI}$ & 0,63 & 0,0001 & 5,39 \\
\hline LIG & 7,23 & 8,02 & 9,11 & 8,59 & 8,33 & $\mathrm{LIG}=8,26$ & - & $0,3470 *$ & 21,38 \\
\hline NIDN & 0,08 & 0,09 & 0,10 & 0,10 & 0,11 & $\mathrm{NIDN}=0,087+0,0005 \mathrm{NI}$ & 0,53 & 0,0002 & 8,30 \\
\hline NIDA & 0,05 & 0,04 & 0,03 & 0,04 & 0,03 & $\mathrm{NIDA}=0,052-0,001 \mathrm{NI}+0,00001 \mathrm{NI}^{2}$ & 0,58 & 0,0002 & 15,11 \\
\hline DIVMS & 33,64 & 41,65 & 40,15 & 41,51 & 44,99 & DIVMS $=34,988+0,322 \mathrm{NI}-0,003 \mathrm{NI}^{2}$ & 0,69 & 0,0001 & 5,46 \\
\hline
\end{tabular}

NI - nível de inclusão; CA - casca de abacaxi; FDN - fibra em detergente neutro; FDA - fibra em detergente ácido; CEL - celulose; LIG lignina; NIDN - nitrogênio insolúvel em detergente neutro; NIDA - nitrogênio insolúvel em detergente ácido; DIVMS - digestibilidade in vitro da matéria seca; $\mathrm{R}^{2}$ - coeficiente de determinação da equação de regressão; $\mathrm{P}$ - nível de significância do modelo de regressão; CV Coeficiente de variação; * - modelo de regressão não significativo $(\mathrm{P}>0,05)$. 
to de diluição dessa fração nas silagens, em função dos teores de LIG contidos no material para ensilagem (Tabela 1), o que pode favorecer o consumo e a digestibilidade desse volumoso pelos micro-organismos ruminais, fatores determinantes para a produção animal satisfatória (Andrade et al., 2010).

Em relação aos teores de NIDN, observou-se comportamento linear crescente $(\mathrm{p}<0,05)$. à medida que aumentaram os níveis de inclusão da casca de abacaxi (Tabela 4), com acréscimo de 0,0005 pontos percentuais para cada $1 \%$ de inclusão do coproduto na silagem. Esse comportamento foi observado em função dos teores encontrados no material ensilado (Tabela 1), que foram muito próximos aos teores encontrados nas silagens.

Verificou-se comportamento quadrático $(\mathrm{P}<0,05) \mathrm{em}$ relação aos teores de NIDA (Tabela 4), com teores mínimos e máximos, de 0,03 e 0,05\%, nas silagens com 50\% do coproduto e nas silagens exclusivas de capim-elefante, respectivamente. Os altos teores de NIDA encontrados no alimento estão associados a sua menor digestibilidade, visto que esta fração é mais resistente à ação dos microorganismos ruminais, por estarem associados à lignina e a outros compostos de difícil degradação (Van Soest, 1994; Machacek \& Kononoff, 2009). No entanto, os baixos teores de NIDA encontrados neste trabalho são insuficientes para comprometer a disponibilidade dos nutrientes para o metabolismo do animal, principalmente quando associados aos teores de DIVMS do coproduto in natura (Tabela 1) e nas silagens (Tabela 4).

Observou-se efeito significativo $(\mathrm{P}<0,05)$ para os teores de DIVMS entre as silagens de capim-elefante, com os diferentes níveis de casca de abacaxi. Segundo a equação de regressão (Tabela 4), verificou-se comportamento quadrático dessa variável, à medida que se aumentou o nível de inclusão, alcançando-se teores próximos a $45 \%$ de DIVMS, quando 50\% de casca de abacaxi foram incluídos. Em contrapartida, as silagens exclusivas de capim-elefante apresentaram baixa DIVMS, chegando a teores próximos de $34 \%$. Por causa dos teores elevados de DIVMS do coproduto (Tabela 1), as maiores proporções da casca de abacaxi favoreceram a DIVMS das silagens (Tabela 4).

\section{CONCLUSÕES}

A inclusão da casca de abacaxi como aditivo na ensilagem capim-elefante, em até $50 \%$ da matéria natural, favoreceu o processo fermentativo dentro dos silos, elevando o valor nutritivo da silagem de capim-elefante quando este apresenta altos teores de MS (acima de 40\%).

Por essa razão, a utilização desse coproduto na silagem possibilita utilizar o capim-elefante em idade avançada, tornando-se estratégia viável no planejamento da produção de volumosos para ruminantes.

\section{AGRADECIMENTOS}

Os autores agradecem à UFVJM - Universidade Federal dos Vales do Jequitinhonha e Mucuri, à Escola de Veterinária da UFMG, à Fundação de Amparo a Pesquisa do Estado de Minas Gerais - FAPEMIG, à Coordenação de Aperfeiçoamento de Pessoal de Ensino Superior - CAPES e ao Conselho Nacional de Desenvolvimento Científico e Tecnológico - CNPq, pelo apoio e suporte financeiro para a execução deste trabalho.

\section{REFERÊNCIAS}

Anderson BE (2000) Use of warm-season grasses by grazing livestock. In: Moore KJ \& Anderson BE (Eds.) Native warm-season grasses: Research trends and issues. Madison, CSSA. p.147-157.

Andrade IVO, Pires AJV, Carvalho GGP, Veloso CN \& Bonomo P (2010) Fracionamento de proteína e carboidratos em silagens de capim-elefante contendo subprodutos agrícolas. Revista Brasileira de Zootecnia, 39:2342-2348.

AOAC - Association Official Analitical Chemists (1995) Official methods of analysis $14^{\mathrm{a}} \mathrm{ed}$. Washington, AOAC. 101p.

Bailey RW (1967) Quantitative studies of ruminant digestion. II. Loss of ingested plant carbohydrates from the reticulo rumen. New Zeland Journal of Agricultural Research, 10:15-32.

Cândido MJD, Neiva JNM, Rodriguez NM \& Ferreira ACH (2007) Características fermentativas e Composição química de silagens de capim-elefante contendo subproduto desidratado do maracujá. Revista Brasileira de Zootecnia, 36:1489-1494.

Cysne JRB, Neiva JNM, Gonçalves JS, Cândido MJD \& Cavalcante MAB (2006) Composição químico-bromatológica e características fermentativas de silagens de capim-elefante contendo níveis crescentes do subproduto da Graviola. Revista Ciência Agronômica, 37:376-380.

Evangelista AR, Abreu JG, Amaral PNC, Pereira RC, Salvador FM \& Santana RAV (2004) Produção de silagem de Capim-Marandu (Brachiaria brizantha stapf cv. Marandu) com e sem emurchecimento. Revista Ciência e Agrotecnologia, 2:446-452.

Ferreira ACH, Neiva JNM, Rodriguez NM, Campos WE \& Borges I (2009) Avaliação nutricional do subproduto da agroindústria de abacaxi como aditivo de silagem de capim-elefante. Revista Brasileira de Zootecnia, 38:223-229.

Freitas SG (2011) Caracterização nutricional da silagem de coprodutos da extração do palmito de pupunha. Dissertação de Mestrado. Universidade Federal de Viçosa, Viçosa. 35p.

Keplin L (2006) Produção de silagem de qualidade e uso de inoculantes. In: Encontro Técnico sobre Conservação de Forragens (Silagens), Nova Odessa. Anais, Instituto de Zootecnia. p. 165 .

Machacek KJ \& Kononoff PJ (2009) The relationship between acid detergent insoluble nitrogen and nitrogen digestibility in lactating dairy cattle. The Professional Animal Scientist, 2:701-708.

McDonald P (1981) The biochemistry of silage. New York, John Wiley \& Sons. 226p.

Minson D J (1990) Forage in ruminant nutrition. San Diego, Academic Press. 483p.

Pacheco WF, Carneiro MSS, Edvan RL, Arruda PCL \& Carmo ABR (2013) Valor nutritivo de silagens de capim-elefante (Pennisetum purpureum, Shum) com feno de gliricídia (Gliricidia sepium (Jacq.) Walp). Revista Verde de Agroecologia e Desenvolvimento Sustentável, 8:240-246. 
Pereira LGR, Azevedo JAG, Pina DS, Brandão LGN, Araújo GGL \& Voltolini TV (2009) Aproveitamento dos coprodutos da agroindústria processadora de suco e polpa de frutas para alimentação de ruminantes. Disponível em: <http:// www.cpatsa.embrapa.br:8080/public_eletronica/downloads/ SDC220.pdf>. Acessado em: 21 de janeiro de 2014

Pompéu RCFF, Neiva JNM, Cândido MJD, Filho GSO, Aquino DC \& Lôbo RNB (2006) Valor nutritivo de silagens de capim-elefante (Pennisetum purpureum Schum.) com adição de subprodutos do processamento de frutas tropicais. Revista Ciência Agronômica, 37:77-83.

SAS Institute Inc. (2002) Statistical Analysis System user's guide Version 9.0. Cary, Statistical Analysis System Institute. 513p.

Silva DJ \& Queiroz AC (2002) Análises de alimentos (métodos químicos e biológicos). $3^{\mathrm{a}}$ ed. Viçosa, UFV. 235 p.
Tilley JMA \& Terry RA (1963) A two-stage technique for the in vitro digestion of forage crops. Journal of the Brithish Grassland Society, 18:104-11.

Tomich TR, Pereira LGR, Gonçalves LC, Tomich RGP \& Borges I (2003) Características químicas para avaliação do processo fermentativo: uma proposta para qualificação da fermentação. Corumbá, Embrapa. 20p. (Documentos, 57).

Van Soest PJ, Robertson JB \& Lewis BA (1991) Official for dietary fiber, neutral detergent fiber and nonstarch polysaccharides in relation to animal nutrition. Journal Dairy Science, 74:35833597 .

Van Soest PJ (1994) Nutritional ecology of the ruminant. $2^{\mathrm{a}}$ ed. Ithaca, Cornell University Press. 476p. 